\title{
A efetividade dos mecanismos de proteção do patrimônio cultural na preservação da memória coletiva
}

\author{
The effectiveness of the mechanisms of protection of cultural heritage in preserving the \\ collective memory
}

\begin{abstract}
Rosilene Paiva Marinho de Sousa Doutora em Ciência da Informação pela Universidade Federal da Paraíba - UFPB.

E-mail: adv.rpmsousa@gmail.com

Carlos Xavier Azevedo Netto Doutor em Ciência da Informação pela Escola de Comunicação/IBICT. Professor da Universidade Federal da Paraíba - UFPB.

E-mail: xaviernetto@gmail.com
\end{abstract}

\author{
Bernardina Maria Juvenal Freire de Oliveira \\ Doutora em Letras pela Universidade Federal da Paraíba - UFPB. \\ Professora da Universidade Federal da Paraíba - UFPB. \\ E-mail: bernardinafreire@gmail.com
}

\section{Resumo}

Analisa os mecanismos de proteção aplicados ao patrimônio cultural brasileiro buscando para uma compreensão mais apurada, apresentar a proteção do referido patrimônio histórico no Brasil. Nesse sentido, apresenta uma visão de como o patrimônio cultural se apresenta nos dias atuais, bem como a influência da informação patrimonial na garantia da memória, e da construção da identidade. No que tange ao percurso metodológico, trata-se de uma pesquisa exploratória, bibliográfica e documental. Ao final, será realizada uma abordagem crítica, buscando discutir a efetividade dos mecanismos de proteção do patrimônio histórico brasileiro, exemplificativamente o inventário, registros, vigilância, tombamento desapropriação, para a preservação e conservação do patrimônio cultural e se os mesmos contribuem para a preservação da memória histórica e social.

Palavras-chaves: Mecanismos de Proteção do Patrimônio Cultural. Informação Patrimonial. Memória Histórica e Social.

\begin{abstract}
Analyzes the mechanisms of protection applied to the Brazilian cultural heritage aiming for a more accurate understanding, presenting the protection of heritage in Brazil referred to. In this sense, presents a vision of how the cultural heritage is presented in the present day, as well as the influence of heritage information in memory, and assurance of identity construction. With regard to the methodological path, this is an exploratory research, bibliographical and documentary. In the end, will be held a critical approach, seeking to discuss the effectiveness of the mechanisms of protection of the Brazilian historical heritage, as for example the inventory records, surveillance, tipping expropriation for the preservation and conservation of cultural heritage and if they contribute to the preservation of the historical and social memory.
\end{abstract}

Keywords: Cultural heritage protection mechanisms. Information Heritage. Historical and Social memory. 


\section{Introdução}

As influências sofridas pelo Brasil no processo de sua colonização são refletidas intimamente nos aspectos da sua formação cultural. Esse processo, desde a chegada dos portugueses contando com as várias invasões europeias bem como pela chegada dos africanos, propiciou uma conformação cultural significativa nas Américas. Essa conformação estava envolvida nas próprias ações de desenvolvimento econômico do país, promovendo uma troca de experiências cotidianas, geradoras de cultura entre os povos.

Pode-se compreender a cultura como um fenômeno coletivo, cuja origem, manutenção e transmissão estão no encargo dos atores sociais. Para Reale (2012, p. 26) "a cultura existe exatamente porque o homem, em busca da realização de fins que lhe são próprios, altera aquilo que lhe é 'dado', alterando-se a si próprio”. Seguindo esse entendimento, percebe-se que a cultura apresenta-se como elemento essencial para a definição da natureza humana, bem como a força dominante na história, que exibe uma ideia de valor e de fim como instrumento de adaptação.

Nesse contexto, o comportamento humano não pode ser entendido isoladamente, em face do caráter eminentemente coletivo das ações dos indivíduos dentro dos contextos sociais. Isso se reflete na ideia de Mintz (2010), ao esclarecer que cada grupo humano tem sua cultura e não hierarquias de culturas, conduzindo da prática da cultura considerando a capacidade de aprender e assinalar todas as culturas numa multiculturalidade que avança em ritmos diferentes, em distintas partes do mundo.

Essas considerações conduzem ao direcionamento sobre o processo que possibilitou delinear a proteção do patrimônio cultural no Brasil nos dias atuais. A influência cultural de diversos povos permitiu o enriquecimento na formação das diversidades de bens culturais brasileiros de natureza material e imaterial, existentes e reconhecidos. Desse modo, este trabalho busca refletir sobre as formas de preservação e conservação do riquíssimo conjunto que forma toda a gama do patrimônio cultural brasileiro contribuindo dessa forma para a preservação da memória histórica e social.

Isto só se torna possível a partir da abordagem sobre a relação entre patrimônio, memória e a mediação destes para a construção da identidade, a partir do que Sousa, Oliveira e Azevedo Netto (2015), denominam de informação patrimonial. Desta forma, os referidos 
autores apresentam a influência da informação patrimonial na socialização da informação para garantia da memória, vista esta, como suporte de aspectos característicos que utilizam da referida informação para ser exercitada, bem como para a construção da identidade, que se constitui das várias experiências que o homem vai produzindo ao longo de sua vivência.

\title{
2. A proteção do Patrimônio cultural no Brasil
}

Para se delinear a proteção do Patrimônio Cultural Brasileiro, necessário se faz compreender o conceito de patrimônio cultural.

\section{$2.1 \mathrm{O}$ conceito de patrimônio cultural}

Inicialmente, importante se faz destacar que o conceito do termo patrimônio varia em conformidade com o campo em que se aplica. Conforme explica Gonçalves (2002, p. 22-23),

\begin{abstract}
'Patrimônio' está entre as palavras que usamos com mais frequência no cotidiano. Falamos dos patrimônios econômicos e financeiros, dos patrimônios imobiliários; referimo-nos ao patrimônio econômico e financeiro de uma empresa, de um país, de uma família, de um indivíduo; usamos também a noção de patrimônios culturais, arquitetônicos, históricos, artísticos, etnográficos, ecológicos, genéticos; sem falar nos chamados patrimônios intangíveis, de recente e oportuna formulação no Brasil. Parece não haver limite para o processo de qualificação dessa palavra.
\end{abstract}

O referido autor coloca o patrimônio como categoria de pensamento que perpassa todo o tipo de sociedade humana a qualquer tempo e que resultam de processos de transformação em continua mudança, como forma de representação de memórias e identidades.

Gonçalves (2002, p. 23), expõe que “[...] É possível transitar de uma a outra cultura com a categoria patrimônio, desde que possamos perceber as diversas dimensões semânticas que ela assume e não naturalizemos as nossas representações a seu respeito". Evidencia-se nesse sentido, a natureza representacional do patrimônio enquanto símbolo de determinada sociedade ou segmento.

A construção de significado de patrimônio se dá de modo contextual dependendo da posição e do momento de quem faz essa simbolização e está sujeito a influências espaciais e temporais, tratando-se de uma construção histórica e culturalmente determinada. 
Conforme expõe Popp e Parodi (2012), o conceito de patrimônio utilizado no Direito Civil, revela-se incoerente da visão antropocêntrica desejada no discurso jurídico por considerarem-se somente os bens e direitos economicamente apreciáveis.

Na Constituição Federal, o emprego do termo patrimônio passa a ser utilizado em sentido amplo, e não em sentido estritamente jurídico, conforme coloca Reale (2012), ao esclarecer que surge para indicar uma riqueza que o governo e o povo devem preservar, sem perda, de seu adequado aproveitamento econômico.

Segundo Venosa (2004, p. 298), os direitos do patrimônio são formados pelo conjunto de direitos reais e de direitos obrigacionais ou pessoais. Nesse sentido compreende por patrimônio:

[...] O patrimônio é o conjunto de direitos reais e obrigacionais, ativos e passivos, pertencentes a uma pessoa. O patrimônio engloba tão-só os direitos pecuniários. Os direitos puros da personalidade, por nós já referidos, não devem ser considerados como de valor pecuniário imediato. (VENOSA, 2004, p. 298).

Da mesma forma, atribuindo valor eminentemente econômico ao termo patrimônio, o Ministério da Fazenda Nacional, em seu glossário, conceitua o termo patrimônio como conjunto de bens, direitos e obrigações de uma entidade. (BRASIL, 2015, online).

A Constituição Federal passa também a apresentar de forma exemplificativa, e não exaustiva, os bens culturais que integram o patrimônio cultural brasileiro como:

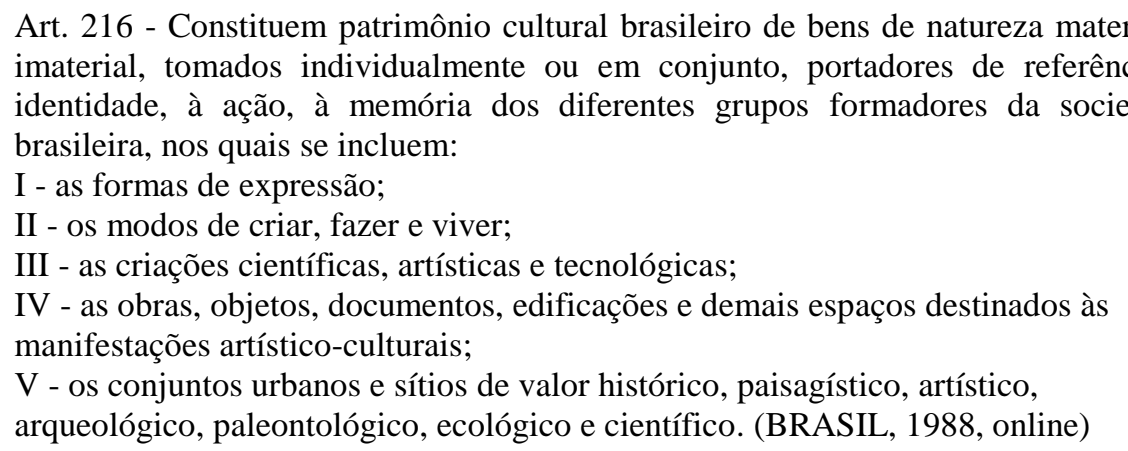

Em face dessa visão, necessário se faz compreender o que se entende por bem cultural, que conforme Souza Filho (1999, p. 42), “é aquele bem jurídico que, além de ser objeto de direito, está protegido por ser representativo, evocativo ou identificador de uma expressão cultural relevante". 
Os bens culturais de natureza material, conforme exposto em Portal Brasil (2009, online), são formados por um conjunto de bens classificados segundo sua natureza:

[...] arqueológico, paisagístico e etnográfico; histórico; belas artes; e das artes aplicadas. Eles estão divididos em bens imóveis - núcleos urbanos, sítios arqueológicos e paisagísticos e bens individuais - e móveis - coleções arqueológicas, acervos museológicos, documentais, bibliográficos, arquivísticos, videográficos, fotográficos e cinematográficos.

Ainda de acordo com o Portal Brasil (2009, online), os bens culturais de natureza imaterial, estão relacionados aos:

[...] saberes, às habilidades, às crenças, às práticas, ao modo de ser das pessoas. Desta forma podem ser considerados bens imateriais: conhecimentos enraizados no cotidiano das comunidades; manifestações literárias, musicais, plásticas, cênicas e lúdicas; rituais e festas que marcam a vivência coletiva da religiosidade, do entretenimento e de outras práticas da vida social; além de mercados, feiras, santuários, praças e demais espaços onde se concentram e se reproduzem práticas culturais.

Conforme Gonçalves (2002), recentemente, construiu-se uma nova qualificação de patrimônio, o denominado patrimônio imaterial ou intangível cuja concepção visa a aspectos da vida social e cultural, dificilmente abrangidos pelas concepções mais tradicionais, opondose ao chamado "patrimônio de pedra e cal".

Seguindo esse entendimento, torna-se importante realizar considerações sobre o termo cultura, de modo a conhecer os elementos que a compõe. Nesse sentido, ao discutir o conceito de cultura, Kuper (2002), descreve a cultura como domínio de configuração simbólica. É um elemento determinante da natureza humana. A questão simbólica é essencial à compreensão social. Nesse sentido, a cultura é compreendida por meio de três elementos: o sujeito, o objeto e o contexto simbólico.

Uma nova ideia de cultura foi lançada por Geertz (2008), no sentido de que a cultura pode ser considerada um sistema de signos passíveis de interpretação. Pode-se afirmar que, a cultura é um fenômeno social, cuja origem, manutenção e transmissão estão na incumbência dos atores sociais.

Atualmente, apesar de cultura ser adaptada, ganhando novos conceitos e categorias e chega ao ponto de já se evitar o termo cultura como oposição a natureza, por que passa a ser compreendida, segundo Adam Kuper (2002), como domínio de configuração simbólica 
considerando-a um elemento determinante da natureza humana. Isto é, passa-se a considerar como cultura o "construído", e a natureza o "dado".

A conexão entre patrimônio e cultura pode ser percebida a partir do conceito de Hungues Varine-Bohan (2001), que apresenta a construção do patrimônio cultural a partir de três elementos, quais sejam, o meio ambiente, o conhecimento humano e os artefatos. Para VarineBohan (2001, p. 177),

O conhecimento humano é intangível, não tridimensional, mas científico, incluindo todas as tecnologias, todas as disciplinas, podendo ser tanto erudito, como popular; o meio ambiente tem origem natural, podendo haver vários entre a natureza virgem e selvagem e aquela civilizada, de certa forma o homem já agiu, em maior ou menor grau, sobre todos os ecossistemas e os modelou; os artefatos, por sua vez, são aqueles bens que o homem produziu, fazendo atuar seus conhecimentos sobre o meio ambiente.

Verifica-se que esses três elementos envolvem os conceitos de patrimônio e cultura, entretanto, o conceito de patrimônio cultural não envolve todas as atividades humanas, tampouco, preservar de todo o bem cultural, isto porque, é a comunidade produtora e legitima beneficiária dos bens culturais, e é através dela que se legitima e se reconhece o patrimônio cultural, considerando o significado para a memória e identidade do povo brasileiro.

2.2 A proteção do patrimônio cultural nos dias atuais

Para se entender o patrimônio cultural no contexto de sua proteção no Brasil, destacase sua relevância quanto a estar, intimamente ligado, conforme coloca Reisewitz (2004, p. 92), a "fatos memoráveis da história do Brasil". Isto porque segundo a autora, era uma forma da elite dirigente, tentar escrever uma história oficial do país. Nesse sentido, o conceito de patrimônio cultural foi sendo definido em conformidade com a sua importância histórica, política e sua evolução jurídica. Nesse sentido, pode-se dizer que o patrimônio cultural exercerá sua função social quando estiver tenuamente relacionado ao elemento cultural. Desse modo, torna-se relevante tecer algumas considerações sobre o patrimônio cultural no Brasil nos dias atuais.

No âmbito internacional, o Brasil é signatário da Convenção sobre a Proteção do Patrimônio Mundial Cultural e Natural (BRASIL, 1977), aprovada pela Conferência Geral da Organização das Nações Unidas para a Educação, a Ciência e a Cultura (UNESCO): 
[...] por esse instrumento estão protegidos monumentos (obras arquitetônicas, de escultura e pintura monumentais, elementos ou estruturas de natureza arqueológica, inscrições, cavernas e grupos de elementos, que tenham valor universal do ponto de vista da História, da Arte ou da Ciência), conjuntos (grupos de construções isoladas ou reunidas que, em virtude de sua arquitetura, unidade ou integração na paisagem, tenham valor universal excepcional do ponto de vista da História, da Arte ou da Ciência) e lugares notáveis (obras do homem ou conjugadas do homem e da natureza, bem como áreas que incluem sítios arqueológicos de valor universal excepcional do ponto de vista histórico, estético, etnológico ou antropológico). (VALENTE; HANDFAS, 2012, p. 276).

A previsão constitucional, que envolve o patrimônio cultural brasileiro, apresenta com clareza o que o legislador pode conceituá-lo como tal. Conforme o artigo 216 da Constituição, o patrimônio cultural constitui-se dos bens de natureza material e imaterial, tomadas individualmente ou em conjunto, portadores de referência à identidade, à ação, à memória dos diferentes grupos que constituem a sociedade brasileira. (BRASIL, 1988).

O conceito delimitado na constituição de 1988, por sua amplitude, pode ser considerado como um dos mais avançados do mundo. Nesse sentido, Rodrigues (2001) expõe que o legislador brasileiro aceitou o moderno conceito de patrimônio cultural como mais englobante, banindo expressões que nos textos constitucionais antigos eram utilizados, como patrimônio artístico, histórico, arquitetônico, arqueológico e paisagístico e abarcando a questão da intangibilidade dessas expressões culturais.

Desse modo, buscou-se delimitar o campo de atuação da proteção ao patrimônio cultural, de modo que bens culturais não se resumem apenas àqueles materializados em objetos físicos, abrangem também os bens imateriais, constituído por elementos, como tradições, folclore, saberes, línguas, festas, manifestações populares, entre outros, passando a receber expressamente a tutela do ordenamento jurídico. Em face dessa visão, por bem cultural, no entendimento de Souza Filho (1999, p. 42), deve-se entender como "aquele bem jurídico que, além de ser objeto de direito, está protegido por ser representativo, evocativo ou identificador de uma expressão cultural relevante".

Percebe-se, desta forma, a magnitude em que o patrimônio cultural passa a ser incluído nas normas brasileiras em face da importância de recolocar e conservar aspectos culturais e históricos do Brasil. Isto torna-se possível por meio da memória histórica e social, e nesse sentido, segundo Elliott (2010, p. 34) a memória pode ser compreendida como "conjunto das informações registradas". 
Conforme exposto em Sousa (2012), a memória poderá dar suporte a determinados aspectos peculiares, como organizações sociais, culturais e políticas que usam a informação para seu funcionamento, havendo assim uma relação própria entre memória e informação.

O direito à informação e o direito à memória, conforme Dantas (2010, p. 68), caracteriza-se enquanto gênero ou espécie de direito fundamental, quando entendido como uma espécie autônoma, sendo o seu conteúdo referente à garantia de acesso aos registros culturais da sociedade, em variadas formas. Já o Patrimônio Cultural pertence ao grupo dos direitos difusos, que materializam poderes de titularidade coletiva pelo uso da memória, possibilitando a construção seletiva do passado, que se converte em informação patrimonial.

Silveira e Lima Filho (2005) colocam que é nesse sentido que é possível falar numa memória que impregna e restitui "a alma nas coisas", isto é, o objeto, enquanto expressão da materialidade da cultura de um grupo social, fortalece o vínculo com o lugar através da memória, que ao ser resignificada retoma lembranças de situações vividas outrora, bem como de seus vínculos com o seu lugar de pertença.

Conforme Miranda (2006), a proteção ao patrimônio cultural satisfaz a humanidade como um todo, na medida em que preserva seus valores, assegurando a sua transmissão as gerações futuras, e consequente construção de identidade. Nesse sentido, pode-se falar no processo de socialização da informação, compreendida por Christovão e Braga (1995, p. 1), como “[...] a construção, tratamento e divulgação da informação de diferentes tipos [...] a partir da definição conjunta por parte de produtores e usuários, que aqui se confundiriam, de suas necessidades, e de quais seriam os caminhos (metodologias) mais adequados para atendê-los". A socialização da informação, ao analisar os mecanismos de proteção do patrimônio cultural em sua efetividade permite que estes sejam vistos como forma de instituir a noção de pertencimento.

\section{A efetividade dos mecanismos de proteção do patrimônio cultural brasileiro}

Envolvendo bens de natureza material e imaterial, o Patrimônio Cultural, para que cumpra sua função de buscarem resguardar a originalidade de fontes históricas e se deixar reconhecer pela sociedade, como conjunto de bens de reconhecido valor que expressam a cultura de um povo, exigem meios eficazes que garantam a sua preservação e conservação. 
Esses meios tornam-se passíveis de eficácia, a partir de normas específicas que garantam sua proteção. Os mecanismos de proteção do patrimônio cultural brasileiro estão previstos no $\S 1^{\circ}$ do artigo 216 da Constituição Federal. Como rol exemplificativo, constituem-se instrumentos de proteção do patrimônio cultural brasileiro, inventários, registros, vigilância, tombamento e desapropriação.

Quanto ao Inventário, o termo etimologicamente, deriva do latim inventarium, para designar "encontrar"; para assinalar uma relação onde se encontravam registrados bens de uma pessoa falecida, de uma empresa ou uma cultura. (FERREIRA, 2010).

Conforme exposto pela Equipe do Patrimônio Histórico e Cultural - EPAHC (2016, online) entende-se por inventário:

[...] um dos instrumentos administrativos de preservação do patrimônio cultural do Município que tem por objetivo preservar, como patrimônio cultural, imóveis de valor histórico, arquitetônico, urbanístico, ambiental, simbólico e também de valor afetivo para a população, impedindo que venham a ser destruídos ou descaracterizados.

Miranda (2006, p. 103), esclarece que “[...] o inventário visa à identificação e ao registro dos bens culturais adotando-se, para sua execução, critérios técnicos de natureza histórica, artística, arquitetônica, sociológica, antropológica, dentre outras." Ainda para Miranda (2006, p.103), o material para fins de inventário podem ser registrados em fichas onde exista "“[...] descrição sucinta do bem cultural, constando importância do mesmo, histórico, características físicas, delimitação e estado de conservação.”.

Embora com previsão constitucional, o inventário não possui regulação infraconstitucional que possa regulá-lo em âmbito nacional. Igualmente, a Constituição possibilita que os estados possam legislar concorrentemente com a União e o Distrito Federal, sobre o assunto. No campo do direito, surge uma celeuma sobre a efetividade desse instrumento em face da necessidade ou não de regulação por lei federal.

Pensando sobre o aspecto da regulação do inventário, e tendo por base a ideia de que o patrimônio cultural brasileiro não se restringe apenas aos bens materiais, como também as manifestações culturais de grupos que compõem a sociedade brasileira, discutiu-se a criação do Inventário Nacional de Referências Culturais. Convencionou-se denominar de referências culturais a ênfase à diversidade não só da produção material, como também dos sentidos e valores atribuídos a bens pelos diferentes sujeitos e práticas sociais. Conforme exposto no INRC 
(2000, p.14), “[...] só se constituem como 'referências culturais' quando são consideradas e valorizadas enquanto marcas distintivas por sujeitos definidos.” Para o IPHAN (2016a, online), o Inventário Nacional de Referências Culturais pode ser definido como:

[...] instrumento de uma política de identificação abrangente, cuja meta é o levantamento e mapeamento de bens culturais significativos para os moradores dos núcleos tombados, dos municípios, dos estados, seja para o reconhecimento como patrimônio nacional, por meio de Registro ou de Tombamento, seja como subsídio ao planejamento de ações de preservação e apoio adequados.

Assegura-se que o INRC tem como característica principal a dinamicidade, uma vez que viabiliza a identificação e documentação de referências significativas para grupos sociais específicos, evitando-se que a produção de um tipo de registro viesse a tornar estático o processo social formador. O referido INRC pode ser descrito a partir de celebrações, formas de expressão, ofícios e modos de fazer, edificações e lugares.

Pode-se dizer que o inventário trata-se de uma modalidade que surgiu para suprir a lacuna da necessidade de se mapear bens que não eram possíveis de ser reconhecidos como patrimônio cultural material através do tombamento.

Ao que se refere aos Registros, como instrumento de proteção do patrimônio cultural tem-se também o Registro de Bens Culturais de Natureza Imaterial, regulamentado pelo Decreto $\mathrm{n}^{\mathrm{o}} 3.551$, de 04 de agosto de 2000.

Brayner (2007, p. 22), ao afirmar que a inscrição dos referidos bens e expressões nos livros de registro, contribuem “[...] para o reconhecimento e a valorização do papel de uma determinada manifestação cultural na formação da cultura brasileira”. Ainda conforme Brayner (2007, p. 22), pode se citar como exemplos de bens culturais registrados como Patrimônio Cultural do Brasil:

[...] o Ofício das Paneleiras de Goiabeiras, em Vitória, no Espírito Santo; a Arte Gráfica Kusiwa, dos Índios Wajãpi do Amapá; o Círio de Nazaré, em Belém; o Samba de Roda do Recôncavo Baiano; o Modo de Fazer Viola-de-Cocho, no Mato Grosso e Mato Grosso do Sul; o Ofício das Baianas de Acarajé; o Jongo no Sudeste;a Cachoeira de Iauaretê - lugar sagrado dos povos indígenas dos rios Uaupés e Papuri, no estado do Amazonas; a Feira de Caruaru e o Frevo em Pernambuco; o Tambor de Crioula do Maranhão; as Matrizes do Samba no Rio de Janeiro: partido alto,samba de terreiro e samba-enredo; o Modo Artesanal de Fazer Queijo de Minas nas Regiões do Serro, na Serra da Canastra e Serra do Salitre, no estado de Minas Gerais, o Ofício dos Mestres de Capoeira e também a Roda de Capoeira; além do Modo de Fazer Renda Irlandesa, tendo como referência este ofício em Divina Pastora, Sergipe. 
Segundo Freire (2005, p. 15), “O Registro de Bens Imateriais, instituído pelo IPHAN em 2000 (Decreto 3.551/00) é um instrumento que propõe a documentação e a produção de conhecimento como formas de preservação", através do registro de informações inerentes à cada manifestação cultural, como cunho identitários e memorialísticos.

A finalidade do registro consiste em reunir a diversidade de criações culturais que constituem o denominado Patrimônio Cultural Brasileiro. Conforme Miranda (2006, p. 106), “[...] o registro identifica a referência cultural e, na medida em que contenha informações relativas aos seus dados históricos e características peculiares, permite o acesso das pessoas às informações necessárias ao conhecimento e divulgação da manifestação cultural.”.

O registro do patrimônio cultural de natureza imaterial pode ser realizado em quatro livros, a saber, o Livro do Registro dos Saberes, onde são realizadas as inscrições de conhecimentos e modos de fazer enraizados no cotidiano das comunidades; o Livro de Registro das Celebrações, no qual registram rituais e festas que envolvem práticas coletivas como trabalho, religiosidade, entretenimento, entre outras; o Livro de Registro das Formas de Expressão, no qual se inscreve manifestações literárias, musicais, plásticas, cênicas e lúdicas; e, o Livro de Registro de Lugares, onde se inscreve feiras, mercados, santuários, praças e espaços onde se concentram e reproduzem práticas culturais coletivas.

Dois aspectos importantes sobre o registro que ainda se deve mencionar, tem previsão no Decreto que o regulamenta, referem-se a: primeiro, que por determinação do Conselho Consultivo do Patrimônio Cultural, outros livros de registro podem ser abertos, em face da existência de possíveis bens culturais que não se enquadram nos livros existentes; e, a necessidade de reavaliação pelo IPHAN, dos bens culturais registrados, pelo período de cada 10 (dez) anos, podendo ser mantido ou não, com o título de Patrimônio Cultural do Brasil. Caso não seja mantido, passa-se apenas a ser registrado como referência cultural a seu tempo.

Através do Decreto $\mathrm{n}^{\circ} 3.551 / 2000$, concebeu-se também o Programa Nacional do Patrimônio Imaterial, cujo objetivo refere-se à criação de uma política nacional de inventário, registro e salvaguarda dos referidos bens culturais, buscando contribuir para a preservação e disseminação de informações sobre o patrimônio cultural brasileiro. No processo de registro dos bens imateriais, se faz necessário a inclusão de projeto, denominado de plano de salvaguarda, que conste uma série de recomendações necessárias para salvaguarda dos mesmos. Segundo Brayner (2007, p. 24), “[...] O plano de salvaguarda indica de que forma o Estado e a 
sociedade poderão agir, a partir daquele momento, para preservar as condições que permitem a continuidade da manifestação cultural registrada.”.

A efetivação do registro se confirma a partir da inscrição de bens e expressões representativos da diversidade cultural brasileira em livros específicos. Com relação a essa efetividade, pode-se questionar segundo Martins (2014), se seria suficiente apenas a manutenção de um rol de elementos que compõe o registro, sem fomentá-los ou divulga-los para que possa se propagar e se perpetuar pelas gerações mais jovens. Outros aspectos também podem ser elencados, a saber, a previsão de um rol restrito de legitimados para realização do registro, impedindo a ampliação do acesso ao processo, bem como, o prazo para reavaliação dos bens, que após reavaliação ocorre apenas mudança de nomenclatura, uma vez que enquanto registrados não se promoveu a noção de pertencimento pela comunidade.

Já a Vigilância, como mecanismo de proteção, conforme Cordeiro (2012, online, grifo do autor), exposto no site do e-gov, encontra-se prevista no Decreto-Lei $n^{\circ}$ 25/1937 estabelecendo que as coisas tombadas devem estar sujeitas " [...] à vigilância permanente do Iphan, que poderá inspecioná-los sempre que for julgado conveniente, não podendo os respectivos proprietários ou responsáveis criar obstáculos à inspeção, sob pena de multa..”.

No entendimento de Miranda (2006, p. 108), a vigilância corresponde a “[...] uma das manifestações do poder de polícia outorgado aos entes federados para que possam tutelar administrativamente patrimônio cultural brasileiro.”.

Nesse sentido, várias categorias do patrimônio cultural podem ser objeto de proteção através do mecanismo da vigilância. Entre essas categorias, como rol exemplificativo, citamse, os bens previstos no artigo 216 da Constituição Federal; os previstos no Decreto-Lei $\mathrm{n}^{\mathrm{o}}$ 25, de 30 de novembro de 1937, que organiza a proteção do patrimônio histórico e artístico nacional; na Instrução Normativa $n^{\circ}$ 01, 11 de junho de 2007, que institui no âmbito do IPHAN o cadastro especial dos negociantes de antiguidades, de obras de arte de qualquer natureza, de manuscritos e livros antigos ou raros, de que tratam os artigos 26 e 27 do Decreto-lei $n^{\circ} 25$ de 1937.

A competência para exercer a vigilância pode ser prevista no artigo 23 da Constituição Federal BRASIL (1988, online), ao determinar a competência comum da União, Estados, Municípios e Distrito Federal para: 


\begin{abstract}
III - proteger os documentos, as obras e outros bens de valor histórico, artístico e cultural, os monumentos, as paisagens naturais notáveis e os sítios arqueológicos;

IV - impedir a evasão, a destruição e a descaracterização de obras de arte e de outros bens de valor histórico, artístico ou cultural;

$\mathrm{V}$ - proporcionar os meios de acesso à cultura, à educação e à ciência;
\end{abstract}

Além disso, o artigo 20 do Decreto-Lei 25/37, determina que os bens tombados, ficam sujeitos a vigilância permanente do Serviço do Patrimônio Histórico e Artístico Nacional, que poderá inspecioná-lo sempre que necessário, sendo impedido a criação de obstáculos por proprietários, sob pena de multa.

Importante destacar que uma característica relevante desse mecanismo de proteção está na necessidade de ser invocado, uma vez que se trata de uma medida administrativa que só exerce sua função quando invocada ou motivada por outrem, isso impõe uma certa falta de efetividade, uma vez que a comunidade desconhece a necessidade de invocação desse instrumento e não encontra investida nesse sentido.

Quanto ao Tombamento, a palavra tombo tem origem portuguesa, significando registro e começou a ser empregado pelo Arquivo Nacional Português, fundado por D. Fernando, em 1375, originalmente instalado em uma das torres da muralha que protegia a cidade de Lisboa, Conhecida posteriormente por Torre do Tombo, onde eram guardados os livros de registros especiais ou livros do tombo. No Brasil, o Decreto-Lei $n^{\circ}$ 25, de 30 de novembro de 1937, adotou tais expressões para que todo o bem material passível de acautelamento, por meio do ato administrativo do tombamento, seja inscrito no Livro do Tombo correspondente. (IPHAN, 2016b, online). Atualmente, o tombamento como instrumento de proteção do patrimônio cultural brasileiro, está previsto no $§ 1^{\circ}$ do artigo 216 da Constituição Federal.

Tombamento pode ser entendido como forma de intervenção na propriedade em que o poder público protege o patrimônio cultural brasileiro, para a preservação da memória nacional. Justificam o tombamento fatores de ordem histórica, artística, cultural, científica, turística e paisagística. (SCATOLINO; TRINDADE, 2015).

$\mathrm{O}$ ato do tombamento apresenta duas características específicas, a saber, entendido como fato e como ato administrativo. No primeiro caso, trata-se de um procedimento material de registro de um bem efetivado pelo agente público no respectivo livro de tombo; no segundo, trata-se de uma restrição imposta pelo Estado ao próprio direito de propriedade, buscando 
preservar os seus próprios atributos. Conforme Miranda (2006, p. 108), para inscrição dos bens protegidos pelo tombamento existem, em nível federal, os seguintes livros:

a) Livro do Tombo Arqueológico, Etnográfico e Paisagístico - para inscrição das coisas pertencentes às categorias de arte arqueológicas, etnográficas, ameríndia, popular, e bem assim os monumentos naturais, os sítios e paisagens que importe conservar e proteger pela feição notável com que tenham sido dotados pela natureza ou agenciados pela indústria humana;

b) Livro do Tombo Histórico - para inscrição das coisas de interesse histórico e as obras de arte histórica;

c) Livro do Tombo das Belas Artes - para inscrição das coisas de arte erudita, nacional ou estrangeira;

d) Livro do Tombo das Artes Aplicadas - para inscrição das obras que se incluírem na categoria das artes aplicadas, nacionais ou estrangeiras.

Quanto aos procedimentos de tombamento, classificam-se em: tombamento de ofício, em que determina que os bens pertencentes à União, Estados e Municípios, se farão de ofício, por ordem do diretor do Serviço do Patrimônio Histórico e Artístico Nacional; o tombamento compulsório, que sobrevém contra a vontade do titular do domínio, quando este oferece resistência, impondo limitação ao uso pleno da propriedade; e, tombamento voluntário, que pode ocorrer a pedido do proprietário.

Quanto aos efeitos, tem-se o tombo provisório e o definitivo. O tombo provisório tratase do procedimento inicial, quando houver a notificação do proprietário para conhecer do processo administrativo e sobre ele se manifestar. $\mathrm{O}$ tombo definitivo passa a ser reconhecido com o encerramento do processo e o bem passa a ser inscrito no livro do tombo.

Ao que se refere o cancelamento do tombamento, questiona-se veementemente a possibilidade de realização do cancelamento por simples ato do Presidente da República. Essa competência tem previsão no Decreto-Lei n ${ }^{\circ} 3.866 / 41$, em que atribui ao Presidente, atendendo a motivos de interesse público, determinar de ofício ou em grau de recurso, o referido cancelamento, referente a bens pertencentes à União, Estados e Municípios, ou a pessoas jurídicas ou naturais de direito privado, realizado no Serviço do Patrimônio Histórico e Artístico Nacional (BRASIL, 1941).

Embora o tombamento possa ser considerado o mecanismo mais concreto de proteção, torna-se importante questionar até que ponto esse instrumento torna-se efetivo na preservação da memória histórica e social. Essa indagação conduz a uma análise no sentido de que a atribuição da disciplina do patrimônio cultural tratada na Constituição, dada a União, aos Estados e Municípios, além da imposição a integração da sociedade ao Poder Público para sua 
efetivação. Entretanto, na prática, percebe-se que a cobrança maior pela preservação recai sobre o cidadão, e o papel do Estado na preservação fica em segundo plano, uma vez que se percebe a deterioração de grandes imóveis tombados, mas que acabam por ruir por falta de manutenção, muitas vezes obrigando seus proprietários a mantê-lo em boas condições. Além disso, as políticas de memória e preservação comumente estão vinculadas às Secretarias de Cultura, e não integrada ao núcleo de Política Urbana dos respectivos municípios, segundo Torres (2013). Desse modo, conforme a referida autora, “[...] em geral, a proteção municipal do patrimônio cultural no âmbito municipal é mais tímida, pois a maioria dos municípios louva-se apenas das leis federais e estaduais para tanto [...]". (TORRES, 2013, online).

Torres (2013, online), acrescenta ainda que,

[...] os governos locais sofrem, ainda hoje, forte pressão política contra a imposição de medidas que de qualquer modo interfiram no exercício do direito de propriedade. Fato que pode ser decisivo na vida política da cidade, já que a pressão exerce influência direta nas eleições municipais.

Essa pressão política, como exemplo, pode ser sentida inclusive, no período da Ditadura Militar, em face dos acontecimentos que envolveram o Palácio Monroe, que foi construído originalmente nos EUA pelo Governo do Brasil, em 1904. Sua estrutura, toda metálica, permitiu seu desmonte para ser remontado no Rio de Janeiro, onde foi sede do Senado Federal, foi destruído com o aval oficial do Presidente General Ernesto Geisel. (O GLOBO, 2017, online).

Por fim, no que se refere ao mecanismo da Desapropriação surge com um instrumento de direito público, em que o Estado priva de forma coativa um bem de seu titular para cumprimento de um fim de utilidade pública, obedecendo como critérios procedimento previsto em lei e o pagamento de justa e integral indenização em favor do proprietário expropriado.

Considera-se bens desapropriáveis qualquer espécie de bens com conteúdo patrimonial, seja móvel ou imóvel, corpóreo ou incorpóreo, e incide sobre o espaço aéreo, subsolo, ações, quotas ou direitos de qualquer sociedade. (SCATOLINO; TRINDADE, 2015).

Para Miranda (2006), em matéria de patrimônio cultural, a desapropriação só deva ser realizada quando indispensável, caso seja absolutamente inviável ou insuficiente às outras formas legais de acautelamento e preservação. Nesse sentido, a desapropriação nos casos de proteção ao patrimônio cultural só deve ocorrer em casos excepcionais. Conforme o referido autor, a desapropriação pode ser aplicada a alguns casos específicos: 


\begin{abstract}
Esse tipo de desapropriação, que não pressupõe o prévio tombamento dos objetos a serem desapropriados, tem sido utilizado principalmente para a preservação dos conjuntos urbanos, com o objetivo de alterar o uso de regiões da cidade de forma que conjuntos históricos e arquitetônicos não sejam deteriorados. Cita-se, por exemplo, o caso do centro histórico de Curitiba que começou a entrar em rápido estágio de deterioração, quando o poder público municipal desapropriou alguns imóveis e deu a eles destinação cultural, invertendo o processo e revitalizando a região. Trata-se de hipótese facultativa de desapropriação, que é inspirada por interesse de proteção do patrimônio cultural e equivale ao chamado tombamento indireto. (MIRANDA, 2006, p. 160).
\end{abstract}

Nesse sentido, os bens, objeto de proteção, correspondentes ao patrimônio cultural, só devem ocorrer, em relação à preservação e conservação dos monumentos históricos e artísticos, isolados ou integrados em conjuntos urbanos ou rurais, proteção de paisagens e locais particulares dotados pela natureza, entre outros.

Toda essa discussão sobre a efetividade do patrimônio cultural brasileiro conduz a destacar a importância da socialização da informação como forma de instituir a noção de pertencimento para que essa efetividade venha a acontecer. A socialização da informação, segundo Loureiro (2002), pode ser compreendida como uma das possibilidades de desenvolvimento da confluência e inter-relação não-hierarquizada de saberes dirigidas à transformação da sociedade.

A noção de pertencimento só se externaliza num movimento dialógico da comunicação, de modo que a mensagem é mediada pela linguagem. Neste sentido, Moraes, Dias e Fiorentini (2006, p. 2), na perspectiva dialógica de Freire, destacam que,

[...] o sentido e a significação dos signos (amplamente entendido como sons, gestos, imagens, palavras e silêncio) dependem da relação entre sujeitos e são construídos na interpretação dos enunciados. Nessa perspectiva o centro da interlocução deixa de estar polarizado entre o eu e o tu, passando a um movimento dialógico na comunicação, ou seja, é criado um espaço entre ambos, como sujeitos empenhados em um entendimento simultâneo, onde cada palavra é resultado de um diálogo, numa relação de força entre o eu e o outro - vozes que representam discursos sociais e consciências inseridas nas classes sociais.

Nessa perspectiva, o patrimônio cultural deve ser visto enquanto exteriorização da materialidade da cultura de grupos sociais que se dá pela inter-relação de saberes, e que para que se tenha a noção de pertencimento, se faz necessário nesse movimento dialógico, reconhecer a informação patrimonial, cujo conceito apresentado por Sousa, Oliveira e Azevedo Netto (2015), coloca como uma mensagem que pode ser transmitida do emissor para o receptor “[...] que é reconhecida através de grupos sociais através de aspectos culturais desenvolvidos a partir de influências políticas, sociais, econômicas ou até mesmo jurídicas que enquanto 
relevantes se perpetuam". São esses aspectos que permitiram a construção de uma identidade, para a preservação de uma memória histórica e social.

\section{Considerações finais}

A pertinência em que se trata o tema patrimônio cultural dentro o contexto da legislação brasileira se dá em face do processo que envolve a evolução do interesse do poder público sobre os bens culturais brasileiros, advindos em função do caráter eminentemente social dos indivíduos.

Não podendo o comportamento humano ser compreendido isoladamente, as relações interpessoais abrem possibilidades para a troca de experiências cotidianas entre os indivíduos, permitindo dessa forma, se perceber o processo de transformação do "dado", refletido pelo estado natural das coisas, para o mundo "construído", transformado pelo homem para adequar às suas necessidades, fazendo-se surgir nesse aspecto a categoria cultura.

O processo de formação cultural brasileiro envolve vários aspectos da vida cotidiana destacando-se principalmente, o que se refere às espécies de bens culturais. As formas de expressão; os modos de criar, fazer e viver; os conjuntos urbanos, sítios de valor histórico, artístico e paisagístico; o patrimônio documental, arqueológico, espeleológico e quilombola, são alguns exemplos da diversidade bens culturais surgidos no processo de desenvolvimento econômico, político e social do país. Nesse sentido, funciona como estratégia de preservação e consequente forma de instituir a noção de pertencimento. Desse modo, o patrimônio cultural exercerá sua função social quando relacionado ao elemento cultura e a socialização da informação, uma vez que sua transversalidade a permite perpassar pelos diversos aspectos das relações humanas.

Embasado nesse pensamento, foi possível estabelecer uma visão atual do reconhecimento do patrimônio cultural brasileiro e a partir de então, tornar possível realizar uma análise sobre a efetividade dos mecanismos de proteção, buscando demostrar a importância dos mesmos para preservação e conservação da memória histórica.

Nesse sentido, tornou-se possível a realização de uma análise da efetividade dos referidos mecanismos como forma de ponderar se os referidos mecanismos realmente atuam no 
sentido da preservação e conservação da memória histórica, com eficiência e eficácia. Percebeu-se, que conforme os exemplos discutidos no texto, como a questão dos registros e de patrimônio material, como o Palácio de Monroe, que a proteção dada ao patrimônio cultural brasileiro, ainda sofre influência de aspectos políticos e por vezes econômicos, que o impedem de efetivamente realizar essa proteção.

\section{Referências}

BRAYNER, N. G. Patrimônio cultural imaterial: para saber mais. Brasília: IPHAN, 2007. Disponível em:

<https://centrodepesquisaeformacao.sescsp.org.br/uploads/BibliotecaTable/9c7154528b82089 1e2a3c20a3a49bca9/138/13767633911715480676.pdf>. Acesso em: 24 jul. 2017.

BRASIL. Decreto Legislativo ${ }^{\circ}$ 74, de 30 de junho de 1977. Aprova o Texto da Convenção Relativa à Proteção do Patrimônio Mundial, Cultural e Natural. Diário Oficial da União, 30 jun. 1977. Disponível em: $\langle$ http://legis.senado.gov.br/legislacao/ListaPublicacoes.action?id=124088>. Acesso em: 25 jul. 2017.

BRASIL. Constituição (1988). Constituição da República Federativa do Brasil. Brasília: Senado Federal: Centro Gráfico, 1988. 292 p.

BRASIL. Decreto-lei No 3.866, de 29 de Novembro de 1941. Dispõe sobre o tombamento de bens no Serviço do Patrimônio Histórico e Artístico Nacional. Diário Oficial da União, 31 dez. 1941. Disponível em: <http://www.planalto.gov.br/ccivil_03/decreto-lei/19371946/Del3866.htm>. Acesso em: 9 maio 2018.

BRASIL. Decreto $\mathrm{n}^{\circ} 3.551$, de 04 de agosto de 2000. Institui o Registro de Bens Culturais de Natureza Imaterial que constituem patrimônio cultural brasileiro, cria o Programa Nacional do Patrimônio Imaterial e dá outras providências. Diário Oficial da União, 04 de agosto de 2000. Disponível em: <http://www.planalto.gov.br/ccivil_03/decreto/D3551.htm>. Acesso em: 29 jul. 2017.

BRASIL. Ministério da Fazenda Nacional. Glossário. 2015. Disponível em: <http://www4.receita.fazenda.gov.br/simulador/glossario.html >. Acesso em: 07 jul. 2017.

CHRISTOVÃO, H. T.; BRAGA, G. M. Socialização da informação: desenvolvimento de metodologias para a sua efetivação: estudo aplicado às áreas de ciência da informação e de saúde. In: ENCONTRO NACIONAL DE PESQUISA EM CIÊNCIA DA INFORMAÇÃO ENANCIB, 2., 1995. Apresentações. Valinhos: ANCIB, 1995. Disponível em: <http://enancib.ibict.br/index.php/enancib/ienancib/search/results >. Acesso em: 09 maio 2018 . 
CORDEIRO, M. Análise dos atuais mecanismos de proteção do patrimônio histórico, cultural, artístico, turístico e paisagístico nacional. In: E-GOV, 2012. Disponível em: $<$ http://www.egov.ufsc.br/portal/conteudo/an\%C3\%A1lise-dos-atuais-mecanismos-deprote\%C3\%A7\%C3\%A3o-do-patrim\%C3\%B4nio-hist\%C3\%B3rico-culturalart\%C3\%ADstico-tur\%C3\%ADst>. Acesso em 15 ago. 2017.

DANTAS, F. S. Direito fundamental à memória. Curitiba: Juruá, 2010.

ELLIOTT, A. G. Informação, imagem e memória: uma análise de discurso em jornais da imprensa negra da Biblioteca da Universidade Federal do Ceará - Campus Cariri. 2010. 111 f. Dissertação (Mestrado em Ciência da Informação) - Universidade Federal da Paraíba, João Pessoa, 2010.

EPAHC. Equipe do Patrimônio Histórico e Cultural. Inventário: o que você precisa saber. Porto Alegre, 2016. Disponível em:

$\langle$ http://lproweb.procempa.com.br/pmpa/prefpoa/smc/usu_doc/inventario.pdf $>$. Acesso em: 05 jun. 2017.

FERREIRA, A. B. H. Dicionário da língua portuguesa. 5. ed. Curitiba: Positivo, 2010. 2222p.

FREIRE, B. M. O inventário e o registro do patrimônio imaterial: novos instrumentos de preservação. Cadernos do LEPAARQ: Textos de Antropologia, Arqueologia e

Patrimônio, Pelotas, v. II, n. 3, jan./jul. 2005. Disponível em: <https://periodicos.ufpel.edu.br/ojs2/index.php/lepaarq/article/view/1047/938>. Acesso em: 24 jul. 2017.

GEERTZ, C. A interpretação das culturas. Rio de Janeiro: LTC, 2008.

GONÇALVES, J. R. S. O patrimônio como categoria de pensamento. In: REUNIÃO ANUAL DA ASSOCIAÇÃO NACIONAL DE PÓS-GRADUAÇÃO EM CIÊNCIAS SOCIAIS, 26., 2002. Mesa-redonda: patrimônios emergentes e novos desafios: do genérico ao intangível. Caxambu: ANPOCS, 2002.

INRC. Inventário nacional de referências culturais: manual de aplicação. Brasília: Instituto do Patrimônio Histórico e Artístico Nacional, 2000. Disponível em:

$<$ http://portal.iphan.gov.br/uploads/ckfinder/arquivos/Manual_do_INRC.pdf $>$. Acesso em : 20 jul. 2017.

IPHAN. Instituto do Patrimônio Histórico e Artístico Nacional. Bens culturais registrados. 2016a. Disponível em: 〈http://portal.iphan.gov.br/bcrE/pages/folInrcE.jsf>. Acesso em: 20 jul. 2017.

IPHAN. Instituto do Patrimônio Histórico e Artístico Nacional. Bens tombados. 2016b. Disponível em: < http://portal.iphan.gov.br/pagina/detalhes/126>. Acesso em: 08 jul. 2017.

KUPER, A. Cultura: a visão dos antropólogos. Baurú: EDUSC, 2002. 
LOUREIRO, J. M. M. Socialização da informação: nadando contra a corrente. Informação \& Sociedade: estudos, v. 12, n. 2, p. 1-11, 2002. Disponível em: <http://www.brapci.inf.br/v/a/7720>. Acesso em: 09 maio 2018.

MARTINS, A. P. B. O Registro como instrumento de tutela do patrimônio cultural imaterial: uma discussão acerca de sua efetividade. Florianópolis: UFSC, 2014. $58 \mathrm{f}$. Trabalho de Conclusão de Curso (Graduação em Direito) - Universidade Federal de Santa Catarina, Floranópolis, 2012. Disponível em:

<https://repositorio.ufsc.br/xmlui/bitstream/handle/123456789/127577/ANA\%20PAULA\%20 BORGES\%20MARTINS\%20-

20Monografia\%20Texto\%20Final.pdf? sequence=1\&isAllowed=y > . Acesso em: 14 ago. 2017.

MINTZ, S. W. Cultura: uma visão antropológica. Tempo, n. 14, Enero-Junio 2010. Disponível em: $<$ http://www.redalyc.org/articulo.oa?id=167013403010> . Acesso em: 28 jul. 2017.

MIRANDA, M. P. S. Tutela do patrimônio cultural brasileiro. Belo Horizonte: Del Rey, 2006.

MORAES, R. A.; DIAS, A. C.; FIORENTINI, L. M. R. As tecnologias da informação e comunicação na educação: as perspectivas de Freire e Bakhtin. UNIrevista, v. 1, n. 3, jun. 2006. Disponível em:

<https://aprender.ead.unb.br/pluginfile.php/125318/mod_folder/content/0/Artigos_de_Raquel _de_Almeida_Moraes/Moraes_e_outros.pdf?forcedownload=1>. Acesso em 10 mar. 2012.

O GLOBO. Monroe. 2017. Disponível em:

<http://infograficos.oglobo.globo.com/rio/especial-monroe.html>. Acesso em: 14 fev. 2017.

POPP, C.; PARODI, A. C. A atual concepção de patrimônio e o direito das coisas. Revista Unicuritiba, Curitiba, v. 1, n. 28, p. 340-377, 2012. Disponível em:

<http://revista.unicuritiba.edu.br/index.php/RevJur/article/view/420 >. Acesso em: 04 set. 2017.

PORTAL BRASIL. Conheça as diferenças entre patrimônios materiais e imateriais. 2009. Disponível em: <http://www.brasil.gov.br/cultura/2009/10/conheca-as-diferencas-entrepatrimonios-materiais-e-imateriais $>$. Acesso em: 06 ago. 2017.

REALE, M. Lições preliminares de direito. 27. ed. São Paulo: Saraiva, 2012.

REISEWITZ, L. Direito ambiental e patrimônio cultural. São Paulo: Juarez de Oliveira, 2004.

RODRIGUES, J. E. R. O patrimônio cultural nos documentos internacionais. In.: DERANI, C.; COSTA, J. A. F. (Org.). Direito ambiental internacional. Santos: Universitária, 2001.

SCATOLINO, G.; TRINDADE, J. Manual de direito administrativo. 3. ed. Bahia: Juspodivm, 2015. 
SILVEIRA, F. L. A.; LIMA FILHO, M. F. Por uma antropologia do objeto documental: entre a "a alma nas coisas" e a coisificação do objeto. Horizonte Antropológico, v. 11, n. 23, p. 15-36, jan./jun. 2005. Disponível em: 〈http://www.scielo.br/pdf/ha/v11n23/a03v1123.pdf >. Acesso em: 09 maio 2018.

SOUSA, R. P. M.; OLIVEIRA, B. M. J. F.; AZEVEDO NETTO, C. X. Informação e patrimônio cultural: uma definição jurídica de informação patrimonial. Perspectivas em Ciência da Informação, Belo Horizonte, v. 20, n. 3, p. 101-115, jul./set. 2015. Disponível em: 〈http://www.scielo.br/pdf/pci/v20n3/1413-9936-pci-20-03-00101.pdf >. Acesso em: 14 ago. 2017.

SOUSA, R. P. M. Memória exercitada: o direito de acesso a informações no âmbito dos arquivos permanentes. 116f. 2012. Dissertação (Mestrado em Ciência da Informação) Universidade Federal da Paraíba, João Pessoa, 2012.

SOUZA FILHO, C. F. M. Bens culturais e a proteção jurídica. 2. ed. Porto Alegre: Unidade, 1999.

TORRES, C. F. S. A efetividade da tutela do patrimônio cultural brasileiro e o Instituto Municipal dos Imóveis Especiais de Preservação. In: ENCONTRO INTERNACIONAL DE DIREITOS CULTURAIS, 2., 2003. Anais... [Fortaleza: Grupo de Estudos e Pesquisas em Direitos Culturais], 2013. Disponível em:

<http://www.direitosculturais.com.br/anais_interna.php?id=3>. Acesso em: 14 ago. 2017.

VALENTE, M. E. A.; HANDFAS, E. R. O patrimônio cultural científico e tecnológico brasileiro e a importância de políticas públicas para sua preservação. Revista Ciências Estratégicas, Colômbia, v. 20, n. 28, p. 271-284, jul./dez. 2012. Disponível em: <http://www.redalyc.org/pdf/1513/151326917005.pdf >. Acesso em: 07 mar. 2016.

VARINE-BOHAN, H. Patrimônio cultural: experiência internacional: notas de aula. In: RODRIGUES, J. E. R. (Org.). Patrimônio cultural: análise de alguns aspectos polêmicos. Revista de Direito Ambiental, São Paulo n. 21, ano 6, p. 177, jan./mar. 2001.

VENOSA, S. S. Direito civil: parte geral. 4. ed. São Paulo: Atlas, 2004. 